\title{
SPASTICITY AND RIGIDITY: AN EXPERIMENTAL STUDY AND REVIEW
}

BY

\section{GEOFFREY RUSHWORTH}

\author{
From the Neurological Research Unit, Churchill Hospital, Oxford
}

With the introduction of the word "tonus" by Mueller in 1838 to describe the slight contractil tension of muscles when at rest, an era of investigation began which was beset with difficulties from its very inception. The failure of exact definition of the term and later the lack of uniformity of definition were only some of them. The principal difficulty, as Fulton (1926) has pointed out, was the failure to recognize and take into account the functional significance of "tonus". It was sought for in all muscles, under all conditions, and at all times, and there is little wonder that controversy was rife. This confusion has even recently been revived again by several workers using electromyography (Hoefer, 1941; Seyffarth, 1942; Weddell, Feinstein, and Pattle, 1944; Floyd and Silver, 1951), this in spite of the numerous attempts of Sherrington (1898, 1915, 1931), Denny-Brown (1929), Cobb, and other great neurologists to clarify the subject. Indeed at the end of the First International Congress of Neurology in 1931, Cobb and Wolff (1932) wrote:

"Confusion of thought has occurred through the diverse use of the term 'tonus'. However carefully defined it now carries with it an incubus of vague connotation which seems to cloud the issue. Its place as a term applied to striated muscle can be more accurately taken over by such specific terms as 'standing reflex', 'postural reflex', and 'righting reflex'. The state of a striated muscle at any moment can be better described by adjectives as slack or taut. Better still the amount of tension can be measured and stated in quantitative terms. We make a plea that the term tone be either discarded or returned to its former home in smooth muscle and kept there."

Unfortunately the term "tonus" is so ingrained in the literature of neurology that it still has a certain utility though it is clear that the clinician often studies two signs, posture and the resistance to passive displacement, which is made up of joint and muscle resistance and the stretch reflex.

The experimentalists of the nineteenth century did, nevertheless, establish certain important facts about the "tonus" of skeletal muscles. Brondgeest (1860) demonstrated its reflex nature in the frog when he showed that the flexed posture of the hind limbs was destroyed by severing appropriate dorsal roots. Later Mommsen (1885) proved that the reflex was not a cutaneous one, as the flexed posture of the frog's hind limbs was maintained after the skin had been stripped off.

That certain diseases of the central nervous system might increase the "tonus" of muscles was recognized, and in 1887 Hughes Bennett read a paper to the Neurological Society of London on "Muscular hypertonicity in paralysis", an "apparently paradoxical condition of increased muscular tonicity as associated with motor weakness". In his paper, Bennett (1888) clearly defined "tonus" and made a number of interesting statements supported only by his own visual observations which were only confirmed more quantitatively in the laboratory many years later. Particularly among these was the conception of a stretch reflex in muscles.

"Healthy muscle contracts when its fibres are subject to sudden stretching. . . . This property is intimately associated with and obeys the same laws as that which has been termed reflex muscular tonicity, or that state of slight constant tension which is characteristic of healthy living muscle. Both are abolished when there is an interruption at any portion of the reflex arc of which muscle is the terminus . . both are increased by causes which augment the excitability of the same reflex mechanism . . . (such) 'as severance from pyramidal tract'."

Much of this must have been speculative, but in 1898 Sherrington published his results of experiments on decerebrate rigidity in the cat, on which he had also repeated the experiments of Brondgeest and Mommsen. The muscular rigidity which characterizes the decerebrate state manifests itself in the posture of the animal and also in the resistance of a limb to passive displacement which is plastic to some extent, but with increasing stretch of the muscles there is a building up of resistance until at some point it suddenly melts. This is the lengthening or clasp knife reaction. The muscular rigidity is present in both extensor and flexor 
muscles but it was greatest in those muscles which oppose gravity. Thus the decerebrate animal assumes a posture which is a caricature of standing head and neck held high, all four limbs firmly extended and tail erect. In other words the normal postural reactions of this animal's muscles were exaggerated.

Denervation of the skin had little effect on the rigidity and an already rigid muscle remained so when its neighbours were denervated. Destruction of appropriate dorsal roots, however, abolishes the rigidity of only those muscles so de-afferentated. Decerebrate rigidity was, in this way, shown to depend on a proprioceptive reflex, the receptor organs of which lie in or near the effector muscle itself.

The effect of acute de-afferentation on decerebrate rigidity, might in part, be explained by operative trauma which was known to affect "tonus" adversely.

Sherrington therefore prepared animals by sectioning dorsal roots some days before decerebration. In these animals the rigidity of the decerebrate state either developed imperfectly or not at all. This perhaps was a preview of the two types of decerebrate rigidity we are now familiar with (Eldred, Granit, and Merton, 1953), one dependent on dorsal root integrity, the other not.

The resemblance of decerebrate rigidity in animals to spasticity in man was quickly recognized, as was the possibility of its alleviation by dorsal root section. Förster, with tremendous courage, tackled the problem and in 1911 published his experience of alternate dorsal root section in 62 spastic patients of varying aetiology. Many of these were children with Little's disease, and Förster was enthusiastic about the results of the operation, and he illustrated the freedom of leg movement and of walking in children who had previously been too spastic to walk. Hey Groves (1911) confirmed Förster's findings on a smaller group of patients. Two years later Förster's experience with the operation had widened considerably, and in his paper to the International Medical Congress (1913a) he reaffirmed the success of the operation but admitted that the spasticity tended to return though there was little regression of the patient's mobility. Over the years Förster's work in this field has been neglected and a full critical appraisal of the method is still lacking.

The effects of dorsal root section on decerebrate rigidity was studied again by Liljestrand and Magnus (1919). They confirmed Sherrington's results and also showed that the injection of small amounts of procaine into the triceps muscle of a decerebrate cat almost abolished the rigidity of the muscle without altering its response to stimulation of the brachial plexus or the reflex changes of tone produced by turning the animal's head. These experiments were a preliminary investigation before the action of procaine on local tetanus was studied. In this case too, intramuscular injection of procaine abolished the muscular spasm of local tetanus.

In 1924, Walshe used this method of procaine injection to study the rigidity of patients with paralysis agitans. Appropriate amounts of procaine injected into biceps and triceps muscle abolished the rigidity and the tendon jerk of these muscles only, but left voluntary power and the tremor undamaged. In three patients with "residual spastic hemiplegia" similar results were obtained.

Liddell and Olmsted (1929) were able to show that the stretch reflex and tendon jerk of a muscle were rapidly abolished reversibly by dilute alcohol, leaving the crossed extension reflex and motor tetanus (elicited central to the partially blocked region) undiminished. Later, Bremer and Titeca (1930) showed that the tendon jerk of the gastrocnemius-soleus and the after-discharge of the crossed extension reflex were selectively paralysed by procaine injected into the muscle.

Liljestrand and Magnus, Walshe, Bremer and Titeca believed their results were due to the selective blocking of the proprioceptive fibres from the muscles and completely analogous to dorsal root section. Liddell and Olmsted explained their results in terms of the increased refractory period of partially blocked nerve which then failed to transmit high frequency discharges. However, Matthews and Rushworth $(1956,1957 a)$ showed that both the stretch reflex and tendon jerk of the soleus muscle of a decerebrate cat were abolished by dilute procaine applied to the muscular nerve at a time when the large motor fibres could be demonstrated to be completely intact. Also it was found that the large proprioceptive fibres originating in muscles are no more sensitive to procaine than are the large motor fibres. This makes the thesis of Liljestrand and Magnus, Walshe, Bremer, and Titeca untenable. On the other hand, the small fibres (gamma fibres) which innervate the muscle spindles are blocked by dilute procaine very readily, as could be seen by recording the ventral root potentials directly or a sample muscle spindle discharge. This latter is high in the decerebrate animal and is responsible for the exaggerated stretch reflexes. It falls sharply to a lower level when the gamma motor fibres are blocked (Matthews and Rushworth, 1958). These results would be in accordance with those of Sarnoff and Arrowood (1947), who injected dilute procaine intrathecally in patients (as a preliminary to the Smithwick operation) and found that the knee and 
ankle jerk disappeared though the muscular power and position sense were still intact. Matthews and Rushworth (1957a) believed that this was due to selective block of the gamma motor fibres by procaine and the experiments of Liljestrand and Magnus, Walshe, Bremer, and Titeca, Liddell and Olmsted were similarly interpreted.

The discovery of Pollock and Davis $(1923,1931)$ that tying both carotids and the basilar arteries in the cat produced a type of decerebrate rigidity, which was little affected by dorsal root section, showed that two distinct forms of decerebrate rigidity existed. Eldred et al. (1953) have since shown that the ordinary decerebrate cat has marked gamma motoneurone activity, whereas the Pollock and Davis animal has very little if any ("alphacat"). Matthews and Rushworth (1957a and 1958) confirmed this with their procaine technique and showed how the decerebrate rigidity of the "gammacat" could be selectively abolished, but in the "alpha-cat" the rigidity only disappeared along with the blocking of large motor fibres (Matthews, 1958).

The experiments to be described in this paper fully confirm the results of Walshe (1924) and they support the suggestion that parkinsonian rigidity and many spastic states depend on the integrity of gamma motor fibres to the muscle spindles. $\mathrm{Be}$ cause of this it is probable that in parkinsonian rigidity and spasticity an increased gamma motoneurone discharge causes a hyperexcitability of the annulo-spinal ending and thus an increased response of the muscle to stretch. Thus in patients with hypertonic muscles, dorsal root section also abolishes the rigidity and spasticity (Förster, 1911, 1913a and b: Pollock and Davis, 1930).

\section{Methods}

Investigation of 50 patients has been completed; 25 had Parkinson's disease (nine post-encephalitic), 20 had spastic limbs (in six patients due to disseminated sclerosis, in five due to cervical spondylosis, three cases of motoneurone disease, four cases of vascular disease of the brain, one case of familial spastic paraparesis, and one case of cerebral palsy). Four had dystonic upper limbs (two with Wilson's disease, two due to cerebral haemorrhage) and one patient was recovering from tetanus.

This investigation began in 1954 principally with a study of the spastic cases, and those selected for study showed spastic involvement of a limb (usually the lower) with clonus on slight stretch, but with preservation of some voluntary movement. This latter was all important as an undiminished power of voluntary action of a muscle group during progressive narcotization of the muscular nerves was taken as indicating that no appreciable number of large (alpha) motor nerve fibres were blocked by the local anaesthetic.
The patients lay in a semiprone position with the limb to be investigated uppermost. Voluntary plantar flexion, the ankle jerk, and clonus were recorded by means of a Russell-Schuster dynamometer which was suitably modified for this purpose. The patient's knee was fixed so that contraction of thigh muscles had no effect on the mechanogram of the ankle movement. When a number of records of voluntary plantar flexion, the ankle jerk, and clonus had been obtained, a partial high sciatic nerve block was begun with $1 \%$ procaine ( $5 \mathrm{ml}$. to $12 \mathrm{ml}$.). Plantar flexion, ankle jerk, and clonus were followed every few minutes until the latter two had been abolished for 10 minutes. Thereafter recordings were taken every 15 minutes or longer until the tendon jerk began to reappear.

In later experiments the dynamometer was replaced by the electromyogram recorded with coaxial needle electrodes from the soleus and gastrocnemius muscles of the same leg. The stretch reflex, ankle jerk, clonus, and maximal voluntary movement were then recorded. The stretch reflex was elicited by slow or fast passive dorsiflexion of the foot. The onset and rate of stretch was signalled from a balloon pressure recorder fixed over the ankle. The tambour of the pressure recorder had a small mirror fixed to its edge, and a beam of light was reflected from this on to a slit at right angles to the cathode-ray tube. A large piece of semireflecting glass at an angle of $45^{\circ}$ superimposed this slit with the stationary spots of the double-beam cathode-ray tube. The electromyogram from the two muscles and the stretch mechanogram were photographed on moving paper by means of a camera specially built for versatility of speed by Dr. Edgar Schuster.

The group of parkinsonian patients, the patients with dystonic limbs, and the patient with tetanus, all had electromyogram recordings of their forearm muscles, usually with two coaxial needle electrodes in bellies of the flexor and extensor muscles of the forearm. A balloon pressure recording system was fixed over the wrist to record passive displacement of the wrist. The excursion of this recorder and the oscillographic recordings of the electromyograms were all simultaneously photographed on moving paper. When recordings of passive flexion and extension of the wrist, voluntary dorsiflexion, and palmar flexion had been obtained, a small volume of $1 \%$ procaine was injected fan-wise around the probable motor point of the extensors of the wrist. Similar recordings were taken thereafter at frequent intervals until the stretch response had vanished. Thereafter recordings were only taken when the stretch response was just returning.

\section{RESULTS}

\section{The Effects of Procaine on Spasticity}

Twenty cases have been studied in detail, but only representative results will be considered as the majority of these cases behaved in a way exemplified by the first three.

Case 1.-T.W., a man aged 48, had a mild spastic paraparesis (left worse than right), due to cervical 


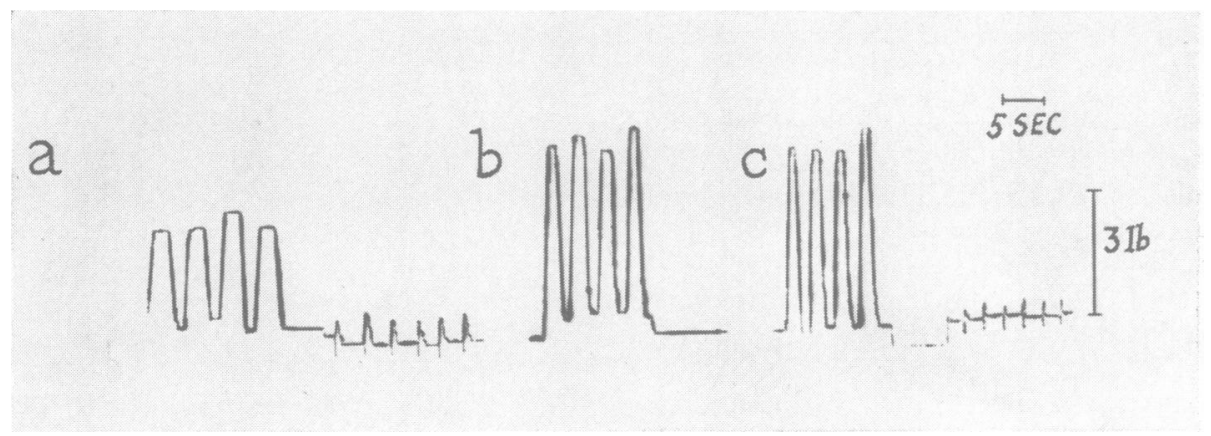

Fig. 1.-Case 1: Dynamometer records of voluntary plantar flexion and the ankle jerk.

(a) Before procaine when clonus was present but not recordable; (b) 30 minutes after the beginning of partial sciatic block with procaine, no ankle jerk or clonus, voluntary power even greater than initially; $(c)$ three-and-ahalf hours after the injection, return of ankle jerk and two beats of clonus.

spondylosis. There was sustained ankle clonus on both sides in response to sudden stretch and the plantar responses were extensor.

During his admission to hospital in June, 1954, mechanical recordings were made of his voluntary plantar flexion and the ankle jerk (Fig. 1). It was not possible to record the clonus as its threshold was greater than the initial tension maintained by the dynamometer. The plantar flexion of the left foot was weak, being less than $3 \mathrm{lb}$., but the ankle jerk was very brisk (Fig. 1a). With the leg still connected to the mechanical recording system, $10 \mathrm{ml}$. of $1 \%$ procaine was infiltrated near the left sciatic nerve using the landmarks detailed for sciatic block by Adriani (1954) and relying on the patient for reports of paraesthesiae in the sciatic distribution. In Fig. 1b the results 30 minutes later are shown. The resistance of the gastrocnemius-soleus muscles had completely disappeared, clonus could not be elicited, the ankle jerk was absent but voluntary plantar flexion was undiminished, if anything increased. The patient said that the movement felt "very relaxed" and though there was no demonstrable impairment of sensation of pinprick or cotton wool the patient complained that the leg felt tingly and slightly numb. It was also perceptibly warmer than the other leg.

Recordings and observations were made periodically and not until three hours later did the ankle jerk reappear. Figure 1c shows the state of affairs three hours and 30 minutes after the procaine injection when the ankle jerks have returned to pre-injection size. Nevertheless the resistance to passive movement at the ankle was small and only two beats of clonus could be elicited on fast stretch. Voluntary power continued to be slightly increased compared with the pre-injection state.

By the following day, the spasticity had returned with brisk ankle jerk, but clonus was ill-sustained.

Case 2.-H.B., a man aged 33, had moderate spastic quadriparesis due to motoneurone disease, with minimal lower motoneurone involvement at this stage.

There was severe ankle clonus bilaterally and he therefore had difficulty in standing.

On February 7, 1956, recordings were taken of voluntary plantar flexion of the left foot. The initial tension of the dynamometer was $4 \mathrm{lb}$. and this was sufficient to elicit continuous clonus, which could, however, be interrupted by the voluntary activity (Fig. 2a). The ankle jerks were scarcely visible against this background of clonus. It was difficult to elicit paraesthesiae from the sciatic nerve so $15 \mathrm{ml}$. of $2 \%$ procaine was infiltrated in the hope that some would diffuse into the region of the nerve. Five minutes later the clonus was distinctly less, the resistance to passive stretch was less, but the voluntary power was little affected (Fig. 2b). Eight minutes after the injection clonus had completely disappeared and the gastrocnemius and soleus muscles were flaccid though a small ankle jerk persisted (Fig. 2c) until 30 minutes after the injection by which time the voluntary plantar flexion was also slightly reduced (Fig. 2d). Four hours later (Fig. 2e) the ankle jerks were fully back but no clonus could be elicited, and there was little resistance offered by the plantar flexors. However, voluntary power had now increased by about $25 \%$ and the patient could walk on his leg with comparative freedom of movement. His other (right) leg, however, still showed severe spontaneous clonus, hyperactive jerks and poverty of movement. Twenty-four hours after the injection (Fig. 2f) the voluntary power of the left plantar flexors was still increased, the ankle jerk was brisk, there was no clonus, and very little resistance to passive stretch. This improvement continued for several days.

These cases illustrate how dilute procaine injected near a nerve trunk can abolish the spasticity, exaggerated tendon reflexes, and clonus without adversely affecting voluntary power. It is an analogous experiment to those reported by Matthews and Rushworth (1957a) on the effect of procaine on the stretch reflex and tendon jerk of the soleus muscle of the decerebrate cat, and those authors did further experiments $(1957 \mathrm{~b}, 1958)$ to support their thesis that gamma motor fibres were preferentially blocked by dilute procaine thus desensitizing the stretch receptors within muscle. 


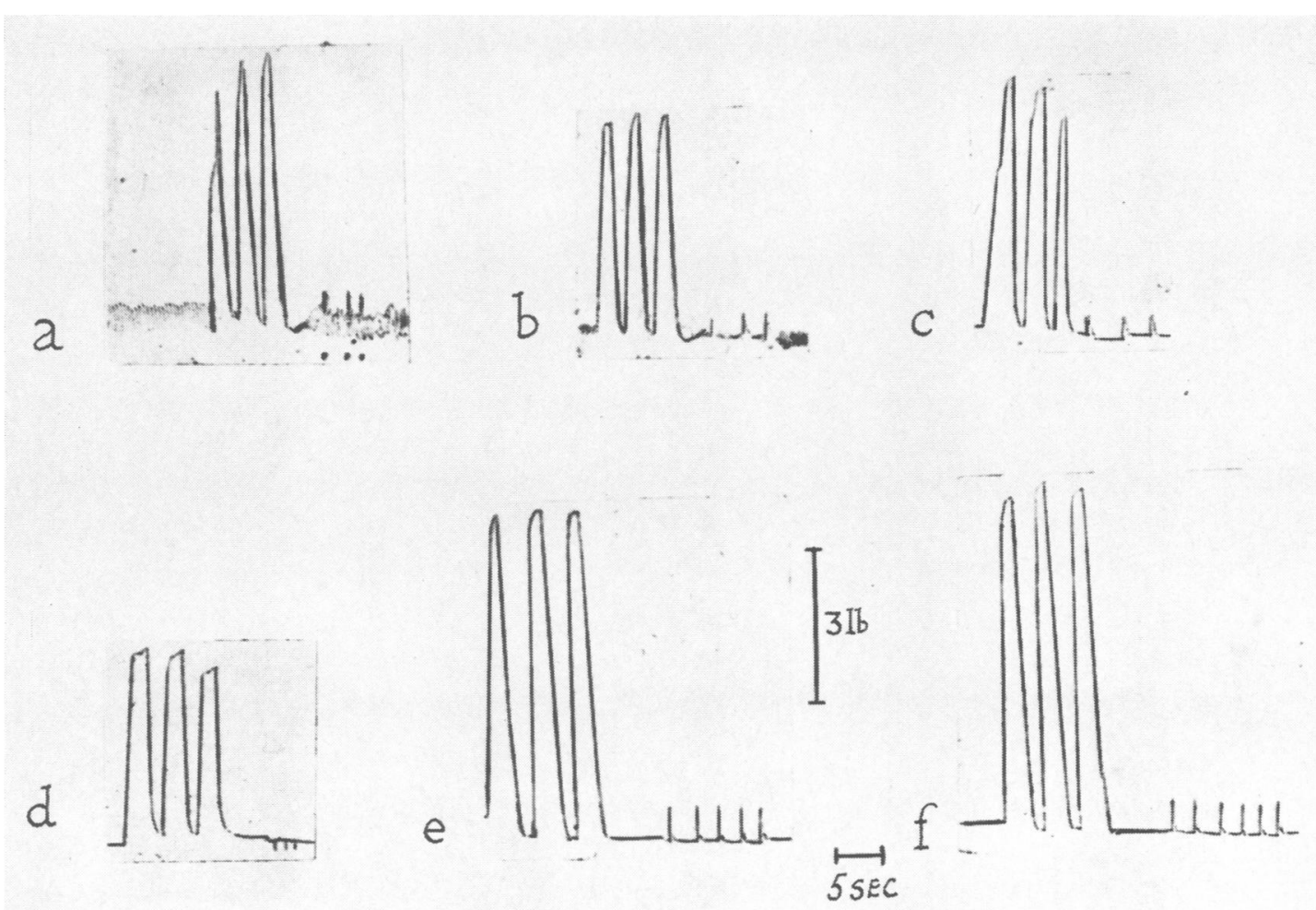

FIG. 2.-Case 2: Recordings of clonus, ankle jerk, and maximal plantar flexion of left foot.

(a) Before procaine, spontaneous clonus at initial tension of dynamometer and ankle jerk (marked by spots) scarcely visible against the background of clonus; $(b)$ five minutes after the procaine injection had been completed; $(c)$ eight minutes after, no clonus; $(d) 30$ minutes after; $(e)$ four hours later, ankle jerks but no clonus, voluntary power larger than initially; $(f) 24$ hours later, no clonus and little resistance to passive stretch.

Another way of showing this phenomenon in man is electromyographically when the stretch reflex, clonus, ankle jerk, and voluntary activity can be recorded from sample motor units.

Case 3.-A.H., a man aged 21 , had had mild difficulty with walking all his life, but nevertheless earned his own living in the family business of building. Indeed other members of the family were affected with this condition of very mild spastic paraparesis. The ankle jerks were very brisk and clonus could be elicited by fast stretch. Electromyograms were recorded from coaxial needle electrodes in the gastrocnemius and soleus muscles of the right leg. Figure 3a shows the activity in the muscles in response to slow stretch with recruitment of motor units to form the tonic stretch reflex. In Fig. 3b the electrical activity during maximal voluntary activity is shown, and in Fig. 3c the clonic response of the soleus and gastrocnemius muscles to fast stretch. The ankle jerk, which gave brief biphasic potentials interrupting the clonus and followed by a silent period, is shown in Figs. 3d and e.

Then dilute procaine was injected around the sciatic nerve resulting 10 minutes later in an abolition of the stretch response in soleus muscle and only a single unit firing in gastrocnemius (Fig. 3f). The electrical activity of the ankle jerk is also reduced (Fig. 3g). Finally 15 minutes later (Fig. 3h) the stretch responses in both soleus and gastrocnemius had been completely abolished, but voluntary plantar flexion produced an outburst (Fig. 3i).

This case of familial spastic paraparesis shows again how procaine may differentiate in its action between spasticity (increased stretch reflexes) on the one hand and voluntary activity on the other.

While the majority of patients studied have behaved as Cases 1,2 , and 3 , occasionally the exaggerated ankle jerk has remained so or at some stage increased yet further in size, when clonus and the resistance to passive displacement were completely absent. This no doubt confirms in the human that phasic and tonic stretch reflexes are different reflex mechanisms which nevertheless may have at least some common anatomical pathway.

Case 4.-W.B., a man aged 21, had severe left spastic hemiparesis and partial left hemianaesthesia due to the 


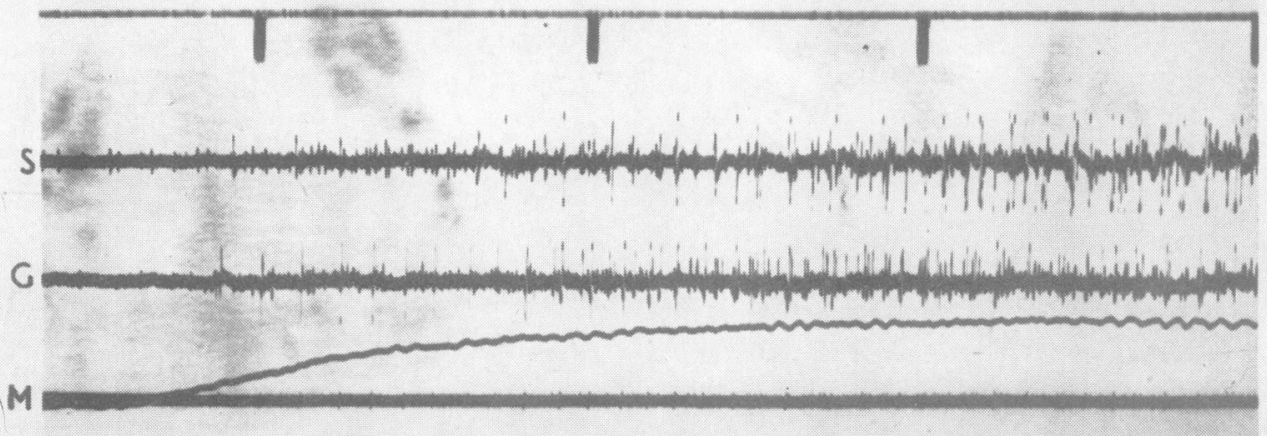

a

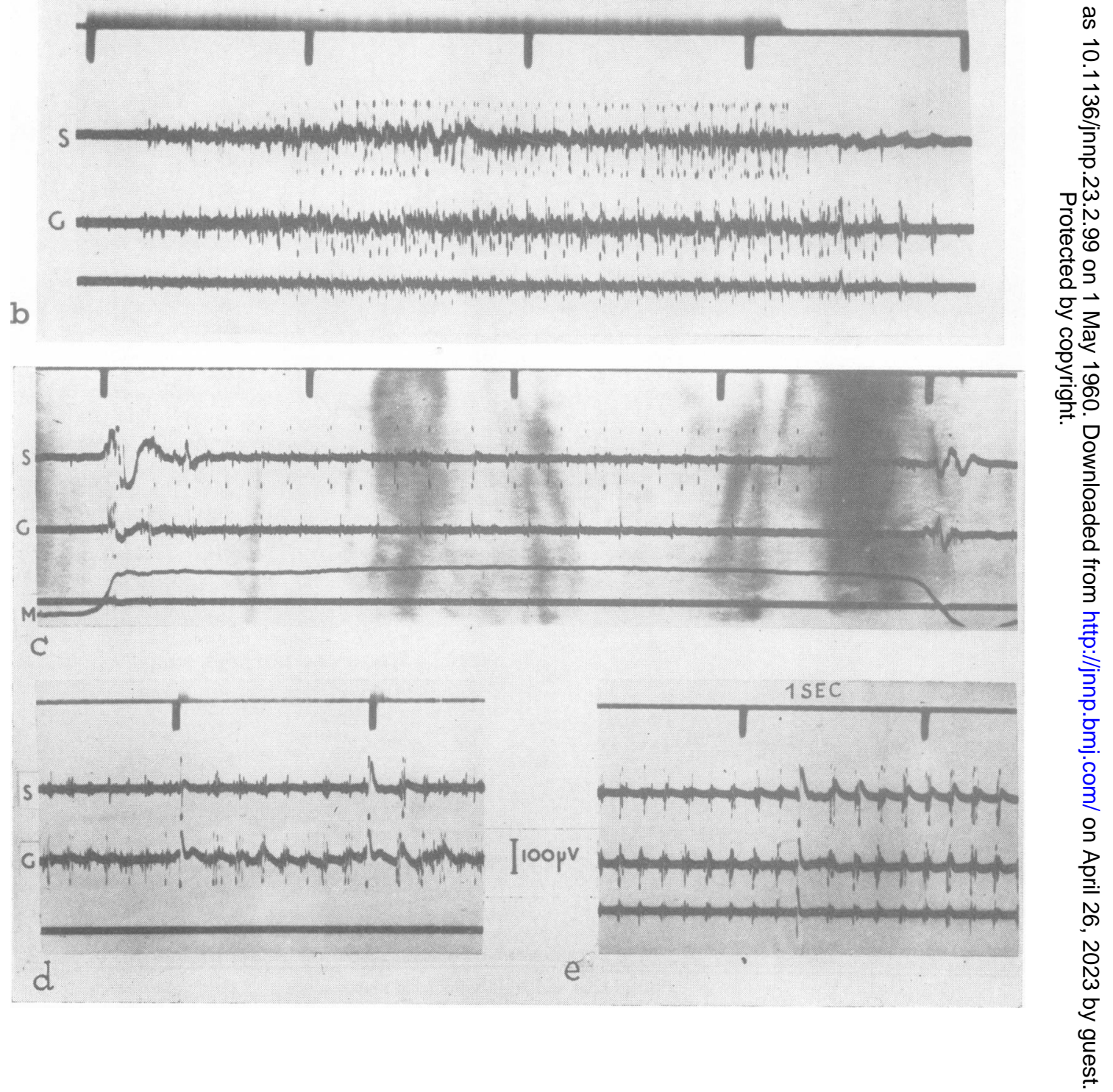



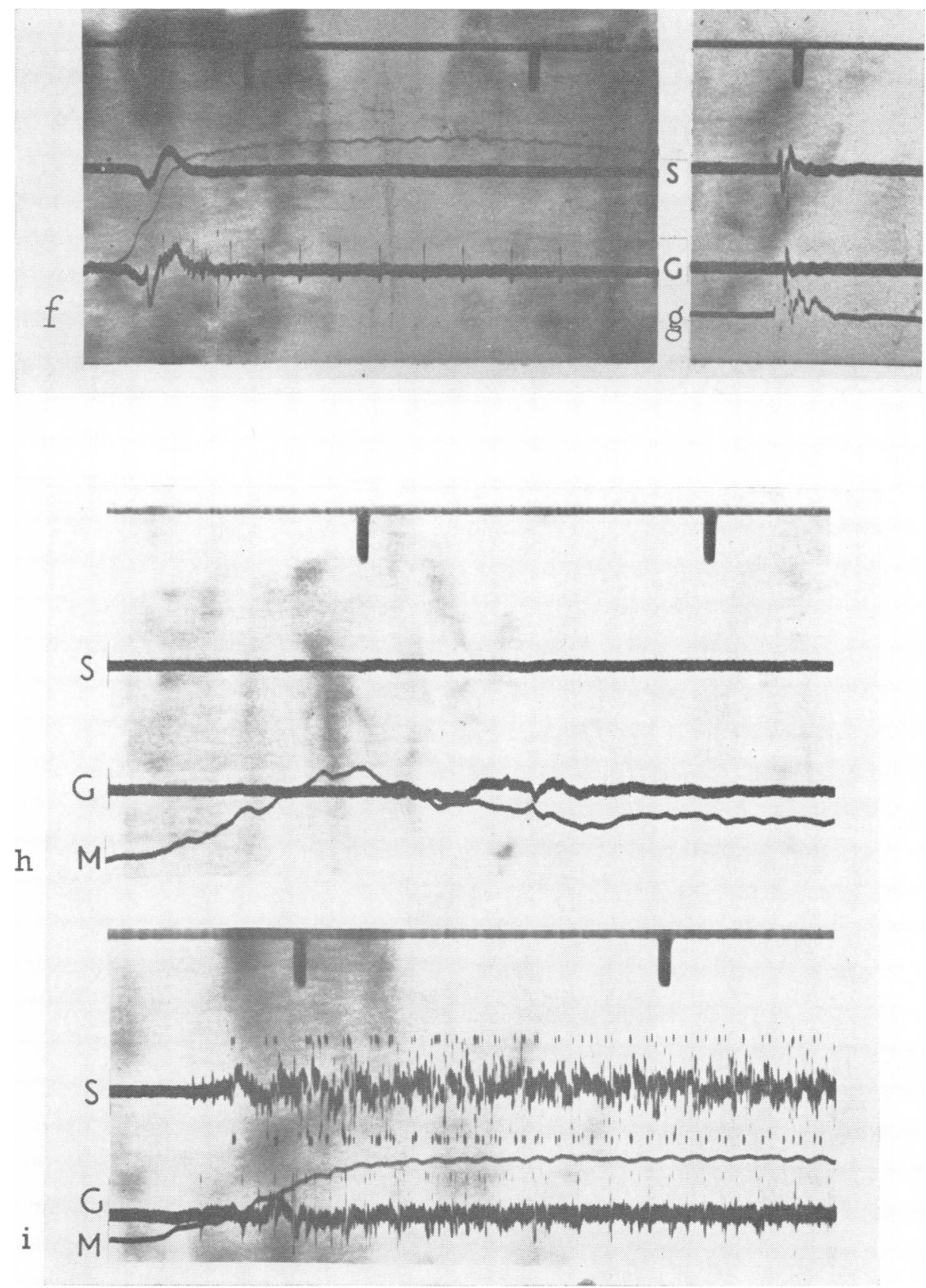

Fig. 3.-Case 3: Electromyograms from right soleus (S) and gastrocnemius (G) muscles, stretch of the muscles being signalled by the mechanogram M, recorded with Prof. D. Denny-Brown

(a) The response to slow stretch before procaine; $(b)$ voluntary activity before procaine; $(c)$ the response to fast stretch before procaine; $(d)$ and $(e)$ ankle jerks superimposed on clonus (the lowest line on these tracings is to be ignored); $(f) 10$ minutes after partial sciatic block with procaine, stretch reflex of soleus absent, that of gastrocnemius reduced to 1 unit; $(g)$ the ankle jerk is also much reduced at this time; $(h) 15$ minutes after procaine, no stretch reflex in either soleus or gastrocnemius; $(i)$ voluntary plantar flexion at this time shows an intense outburst in both muscles. 


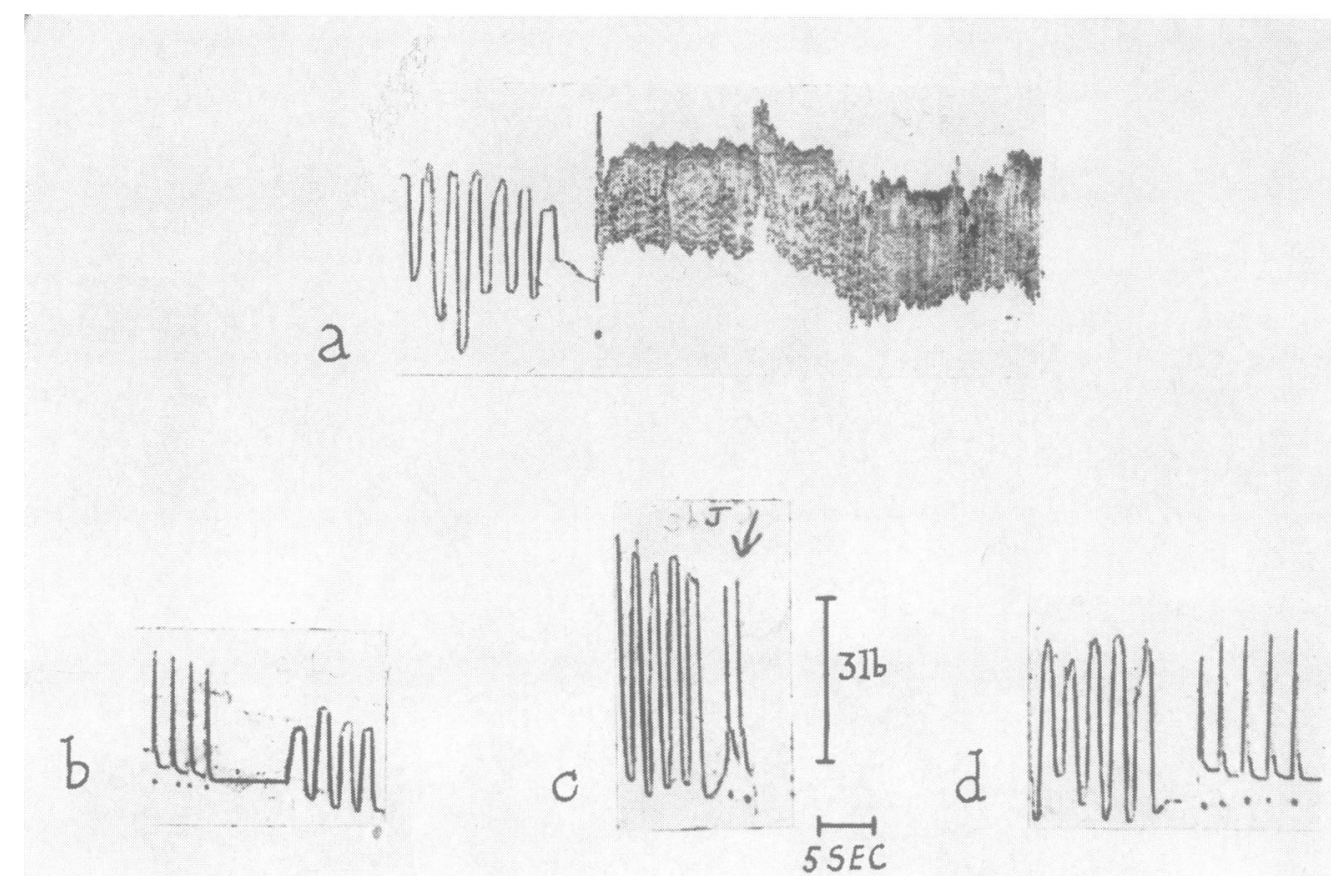

Fig. 4.-Case 4 : Dynamometer records of plantar flexion of left foot, clonus, and ankle jerks.

(a) Before procaine, one ankle jerk throws the plantar-flexors into clonus which was only terminated by disconnecting the patient from dynamometer; (b) 60 minutes after procaine injection, no clonus; $(c)$ three hours later, no clonus, power greater, jerks large; (d) 18 hours later, no clonus, power a little greater than before injection, ankle jerks approach voluntary power in size.

complications of middle cerebral aneurysm. He had severe spontaneous clonus whenever he put his foot to the ground.

On January 11, 1956, recordings of plantar flexions of the left foot were obtained with an initial tension of about $1 \mathrm{lb}$. (Fig. 4a). This was insufficient to induce spontaneous clonus, but a single ankle jerk resulted in maintained clonus which was only terminated by taking the leg out of the dynamometer system.

It was difficult to elicit paraesthesiae from the sciatic nerve due to the partial hemianaesthesia, so $15 \mathrm{ml}$. of $2 \%$ procaine was injected in the region of the nerve with little effect until 60 minutes after injection (Fig. 4b) when the clonus very rapidly declined and disappeared as did the spasticity, and voluntary power was very slightly diminished. The ankle jerk, however, was, at this stage, larger than the voluntary power.

Three hours later, both voluntary power and ankle jerks were larger than in the pre-injection state (Fig. 4c), clonus could not be elicited, and the resistance to passive stretch was slight. This state was little changed 18 hours later (Fig. 4d) and remained so for three days.

Case 5. - This was a study on the right leg of Case 2.

There was a little spontaneous clonus at rest when connected to a dynamometer with an initial tension of $4 \mathrm{lb}$. The ankle jerks were just visible above the clonic base line (Fig. 5a). Good paraesthesiae were obtained from the right sciatic nerve, and $12 \mathrm{ml}$. of $1 \%$ procaine was injected. Five minutes later (Fig. 5b) the voluntary power was reduced slightly, clonus had gone and the ankle jerk was diminished. Ten minutes later the ankle jerk was absent but voluntary power was considerably reduced (Fig. 5c). One-and-a-half hours later in the recovery phase both the voluntary power of plantar flexion and the ankle jerks were increased (Fig. 5d), and two hours later (Fig. 5e) the ankle jerk was even larger and contained a second clonic beat. At this stage, clonus could not be elicited by fast stretch, and the resistance of the plantar flexors to passive displacement was slight. Four-and-a-half hours later both voluntary plantar flexion and the size of the ankle jerk were nearer to pre-injection level (Fig. 5f) and slight resistance to passive displacement of the foot could now be felt, but no clonus was elicitable.

The main findings in these last two cases, that spasticity can be abolished by procaine while sparing voluntary power, is in line with the other experiments and has a similar explanation, but the emergence of the ankle jerk and of voluntary power to a level greater than the pre-injection level is more difficult to explain. The explanation probably lies in the phenomenon of occlusion which occurs when two or more reflexes converge in the same moto- 

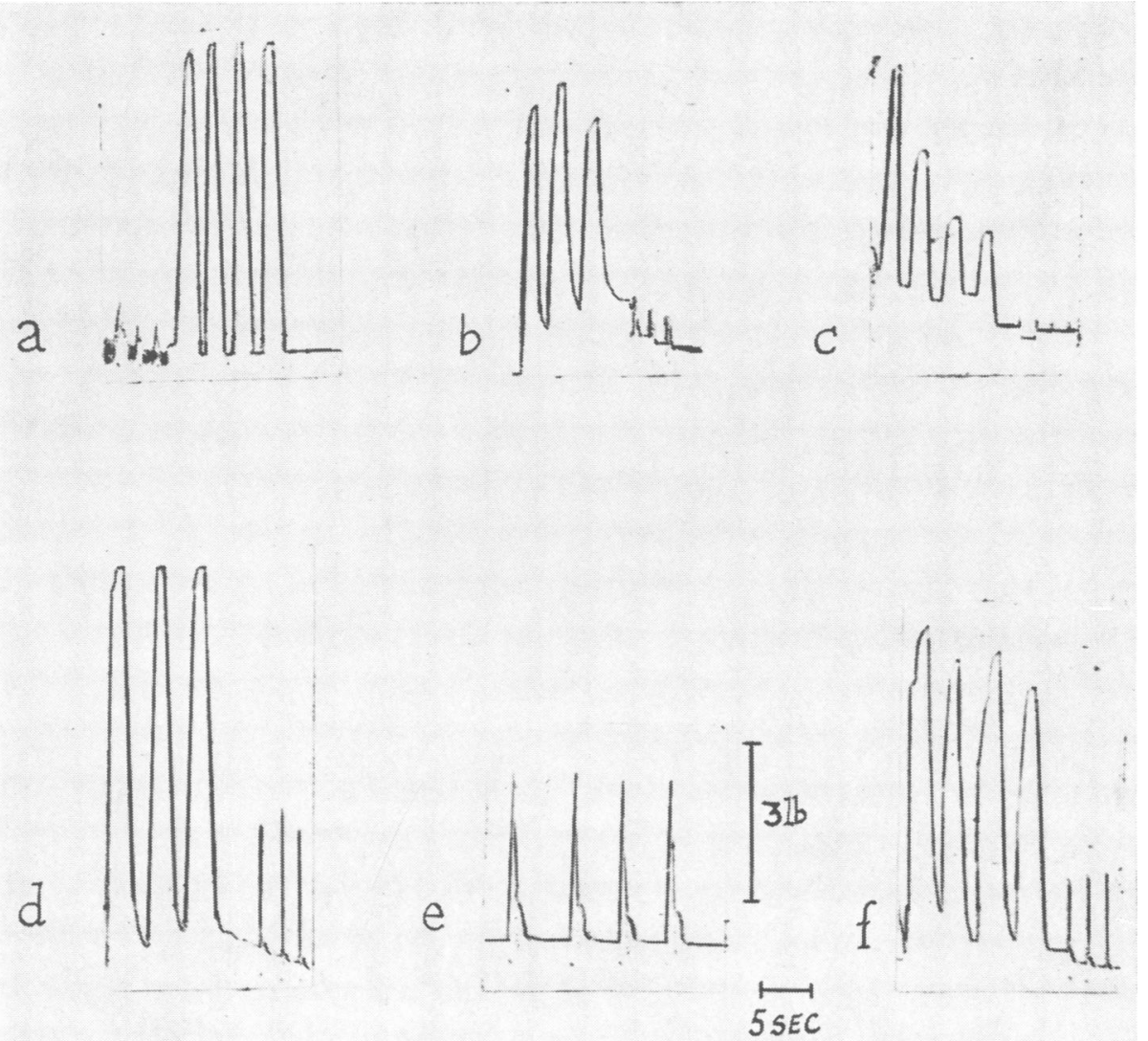

FIG. 5.-Same patient as Case 2 but right leg.

(a) Before procaine, spontaneous clonus, ankle jerks, and voluntary plantar flexion; $(b)$ five minutes after partial block of sciatic nerve with procaine, no clonus; $(c) 10$ minutes later, no clonus, no ankle jerks but voluntary power also reduced; $(d)$ one-and-a-half hours later, no clonus; $(e)$ two hours later, jerks alone with time-base, doubled to show form of reflex response; $(f)$ four-and-a-half hours later, no clonus, but slight resistance to passive stretch.

neurone pool. In the case of the plantar flexors the hyperactive tonic and phasic stretch reflexes are competing with "voluntary activity" for the same motoneurones. This point will be discussed later.

One case behaved quite differently from all the other cases reported above in that procaine only reduced the spasticity and ankle jerk along with the corresponding decrease of the power of voluntary plantar flexion.

Case 6.-C.W., a man aged 31, developed thrombosis of the right vertebral artery resulting in the loss of several right cranial nerves, left hemiplegia, and left hemianaesthesia. After a stormy initial course the patient made a good recovery. Six weeks later the left leg was examined and found to show severe spastic weakness. Recordings of plantar flexion and the ankle jerks were obtained (Fig. 6a). A few beats of clonus were elicited on very rapid stretch, but these could not be recorded. A high sciatic nerve block was then attempted and fair paraesthesiae were obtained before $10 \mathrm{ml}$. of $1 \%$ procaine was injected. Ten minutes later (Fig. $6 \mathrm{~b}$ ) both ankle jerk and voluntary power were reduced by $75 \%$, resistance to passive displacement of the foot was still appreciable, and a few beats of clonus were still elicitable. Fifteen minutes later (Fig. 6c) the ankle jerk was less, there was no clonus and the voluntary power remained grossly reduced. Sixty-five minutes later (Fig. 6d) voluntary power had returned to about $80 \%$ of normal, the tendon jerk had also returned about the same amount, there was much resistance to passive displacement of the foot and a few beats of clonus could be elicited on fast stretch.

This case then showed no differentiation by procaine between the spasticity, tendon jerk, or power. It would appear likely that this man's spasticity was maintained independently of the 


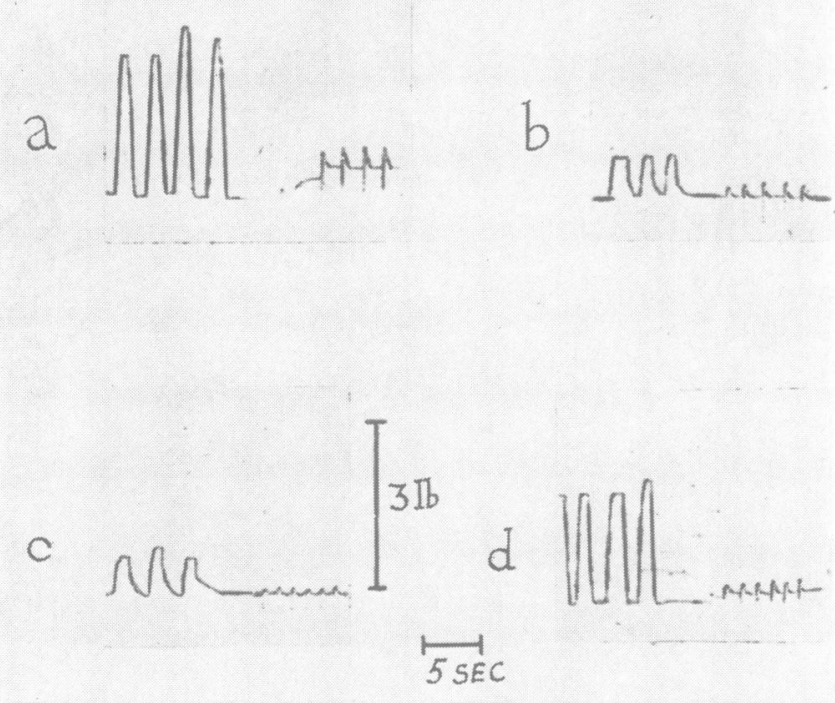

FIG. 6.-Case 6: Dynamometer records of voluntary plantar flexion and ankle jerks.

(a) Before procaine; (b) 10 minutes after partial sciatic nerve block with procaine; (c) 15 minutes afterwards; $(d) 65$ minutes afterwards.

gamma motor fibres and is probably like the Pollock and Davis type of decerebrate cat ("alpha" cat of Granit) studied in this context by Matthews and Rushworth (1957a) and Matthews (1958). Its occurrence in only one case of the present series suggests that it is probably an unusual form of spasticity in man.

\section{Comparison of the Stretch Reflexes of Spasticity and Rigidity}

Before describing the effects of procaine on parkinsonian rigidity the characteristic similarities and differences of the stretch reflex in this condition and in spasticity will be compared and contrasted.

Passive displacement of a spastic limb displays a progressive increase of resistance to stretch of muscle groups, which are usually antigravity muscles. Passive displacement of the limb in the other direction, so as to stretch the antagonists of the antigravity muscles, characteristically encounters little resistance. The resistance of passive displacement of antigravity muscles may increase steeply with each increment of stretch until a certain maximum is reached when the muscles suddenly relax. This is the "clasp knife" or lengthening reaction. It is often difficult to demonstrate in adult spastics owing to the immense size of the stretch reflex in some large muscle groups. It may, under some circumstances, approximate to the maximal tetanic power of the muscles and may thus be very difficult to exceed by the examiner. Fig. 7 shows an electromyogram of a stretch reflex in both heads of the gastrocneumius muscle in a young woman with cerebral palsy. This patient was unable to plantarflex the foot voluntarily and the electromyogram was almost silent during such an attempt, yet the outburst of potentials during maximal stretch shows that reflex motor power is by no means absent.

Fig. 7.-Electromyogram from the lateral and medial heads of the gastrocnemius in a young woman with cerebral palsy. Lateral head upper record. Mechanogram shows the stretch stimulus.

Progressive recruitment and acceleration of units until the lengthening reaction occurs (first dip of the mechanogram).

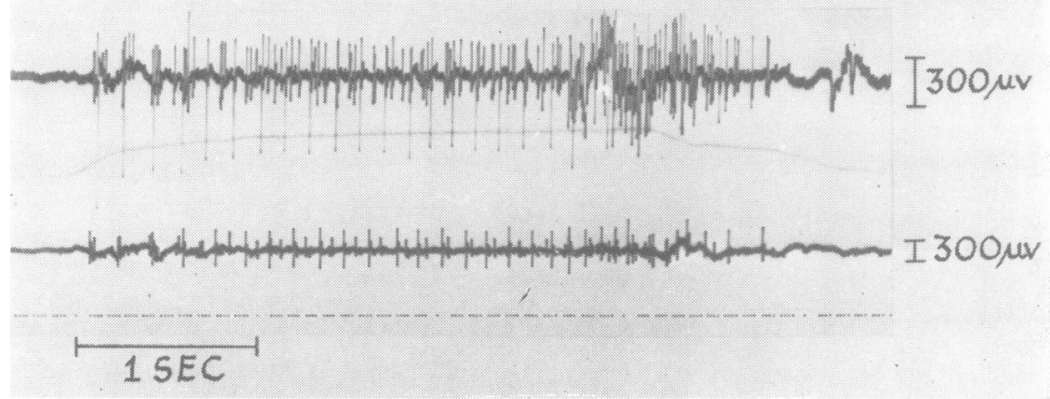


a

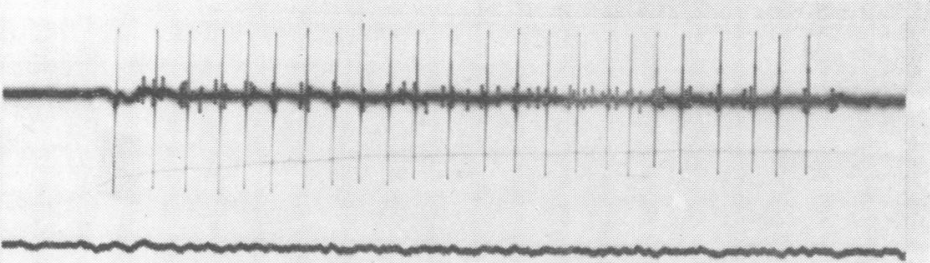

$\mathrm{b}$

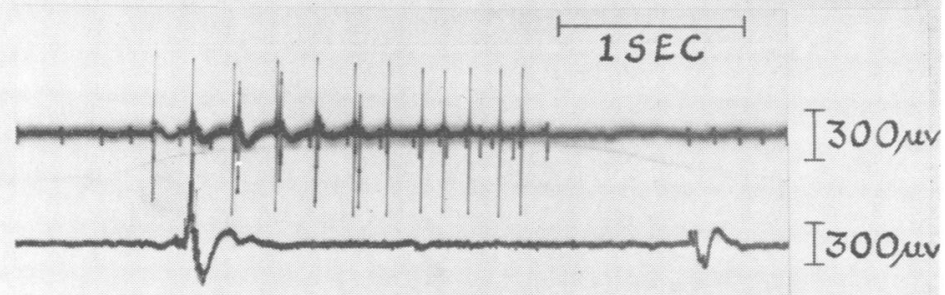

C

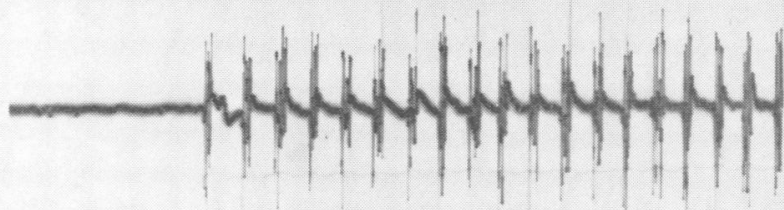

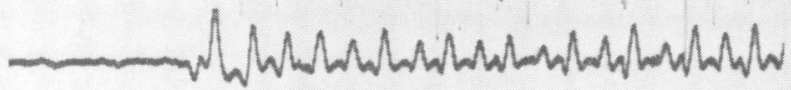

d

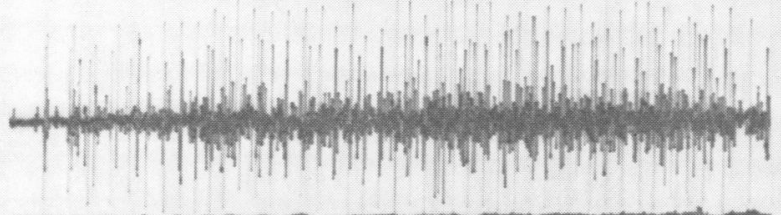

e

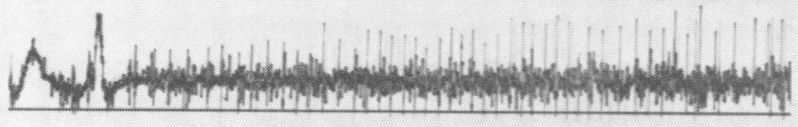

FIG. 8.-Electromyograms from left lateral head of the gastrocnemius (upper line) and the tibialis anterior (lower line) in a man, age 41 , with spastic paraparesis due to disseminated sclerosis. Mechanogram shows passive dorsification of foot.

(a) Slow stretch; (b) faster stretch; (c) fastest stretch; $(d)$ voluntary activity in gastrocnemius; $(e)$ voluntary activity in the tibialis anterior. 
unit is recruited and there are two beats of clonus. Finally with the fastest stretch (Fig. 8c), five units

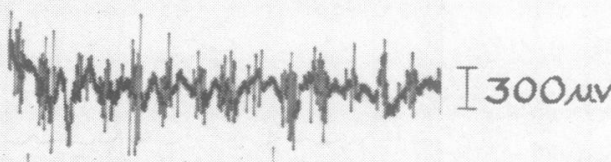
beat in a clonic rhythm of 6 per second. There is no stretch reflex in the tibialis anterior (Figs. 8a, b, and c) though it can be innervated voluntarily by this spastic patient (Fig 8e). During voluntary contraction of the gastrocnemius (Fig. 8d) the units that can be seen firing are probably those that were activated in the stretch reflexes.

The stretch reflex of a muscle group in spasticity may not be inhibited by active contraction of the antagonist, though the law of reciprocal innervation may still hold. This apparently paradoxical situation is illustrated in Fig. 9. The lower record is the electromyogram of gastrocnemius muscle and the upper is that of the tibialis anterior. The patient is gently contracting the tibialis anterior when the gastrocnemius is given an extra passive stretch. This starts off clonus in the gastrocnemius (at the same rate as before, 6 per second), while there are now silent periods in the tibialis anterior record simultaneously with the clonus in its antagonist.

The figure shows the clonic onset of the stretch reflex, then the progressive acceleration and reThus the tibialis anterior is inhibited during each cruitment of motor units to a maximal outburst. With relaxation of the stretching force, the electromyogram becomes silent again.

The intensity of the stretch reflex in spasticity is often proportional to the rate of stretch. In Fig. 8 the stretch reflex is shown electromyographically recorded from the gastrocnemius muscles (top line) and tibialis anterior (bottom line) as the muscle is successively stretched at faster rates. The patient from whom these records were taken was a man aged 41 , with a mild spastic paraparesis due to disseminated sclerosis. With relatively slow stretch a single large unit is seen in the electromyogram (Fig. 8a) and this accelerates as the stretch increases. When the stretch is faster (Fig. 8b) more than one

Fig. 10._-Same case. Coaxial needles in latcral head of the gastrocnemius (upper line) and medial head of the gastrocnemius (lower line).

(a) The response to slow stretch;

(b) the response to fast stretch;

(c) the ankle jerk; (d) voluntary plantar flexion.

a.

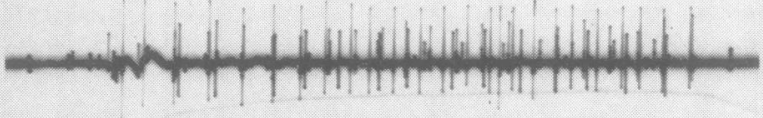

b
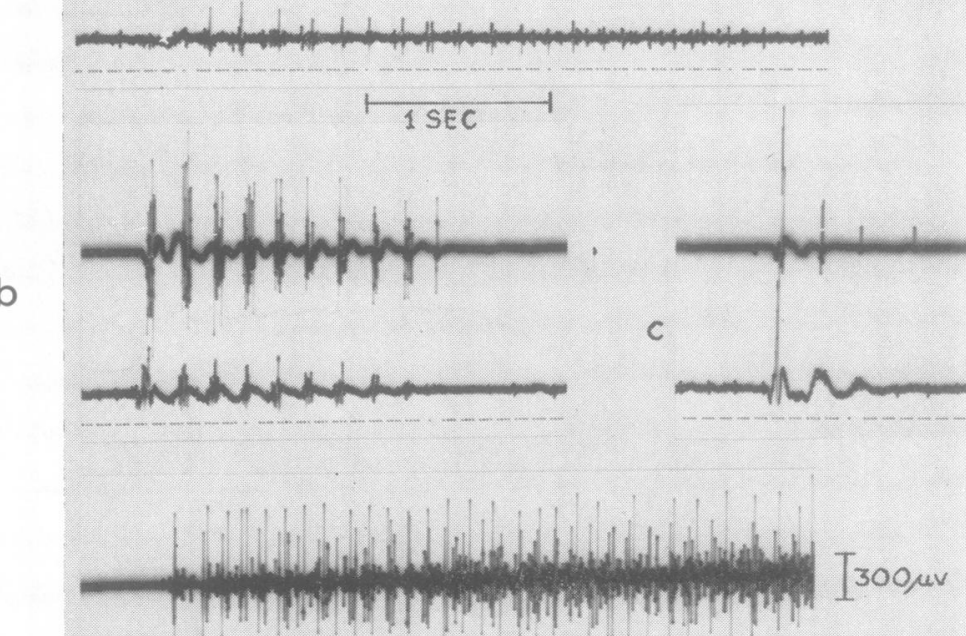

d

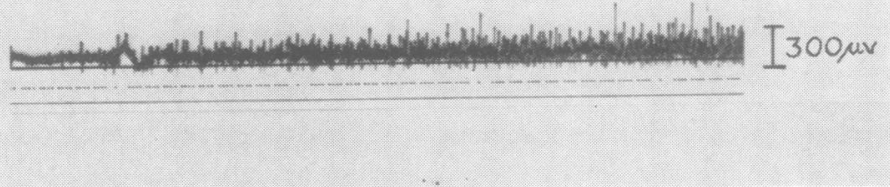




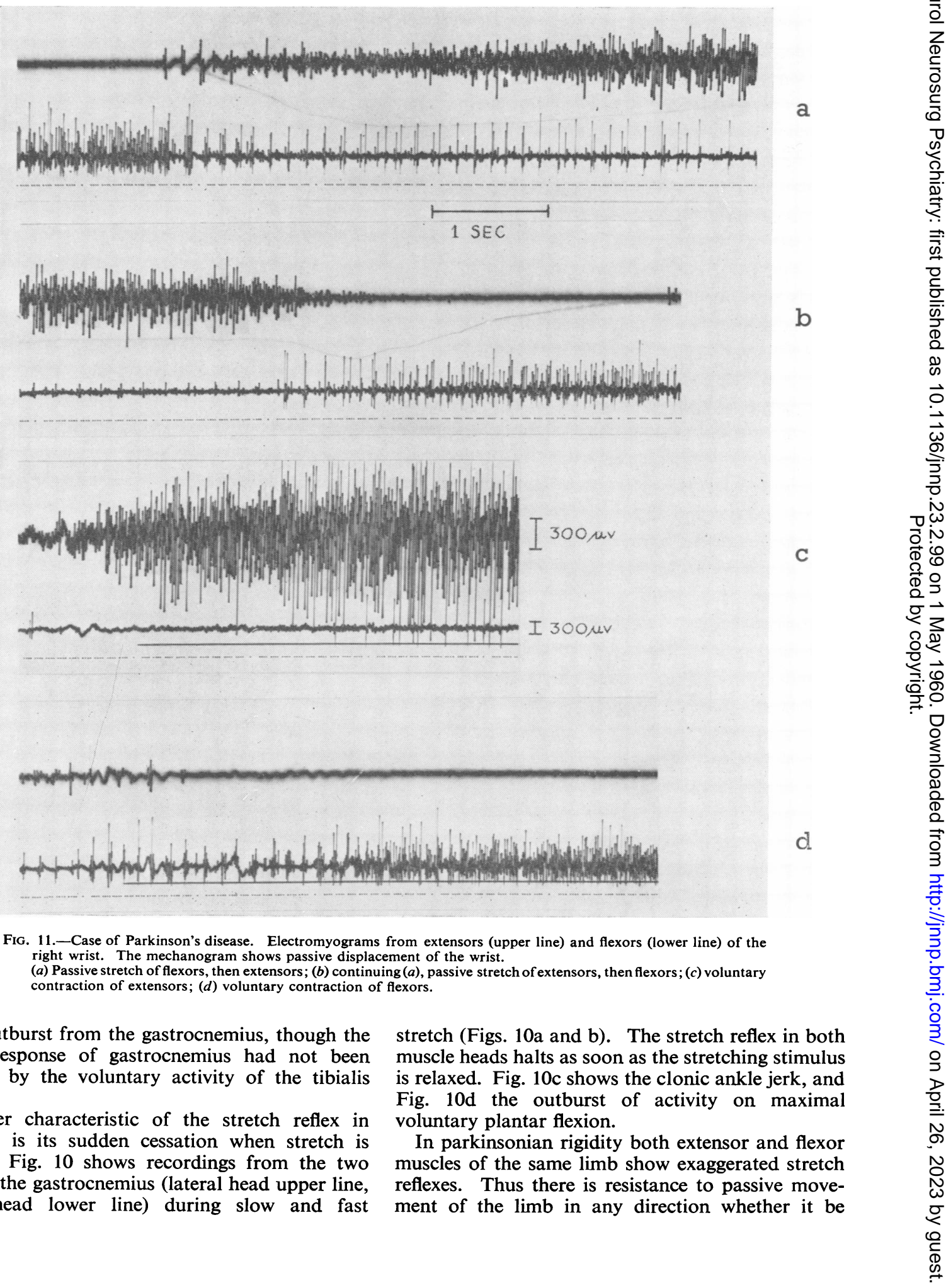

clonic outburst from the gastrocnemius, though the stretch response of gastrocnemius had not been inhibited by the voluntary activity of the tibialis anterior.

Another characteristic of the stretch reflex in spasticity is its sudden cessation when stretch is relaxed. Fig. 10 shows recordings from the two heads of the gastrocnemius (lateral head upper line, medial head lower line) during slow and fast 3 stretch (Figs. 10a and b). The stretch reflex in both muscle heads halts as soon as the stretching stimulus is relaxed. Fig. 10c shows the clonic ankle jerk, and Fig. 10d the outburst of activity on maximal plantar flexion.

In parkinsonian rigidity both extensor and flexor muscles of the same limb show exaggerated stretch reflexes. Thus there is resistance to passive movement of the limb in any direction whether it be 
passive flexion or passive extension. Furthermore, parkinsonian rigidity is plastic in that the limb once displaced tends to stay there. All these features are reflected in the electromyogram (Fig. 11). This record was taken from the flexor (lower line) and extensor muscles (upper line) of the wrist in a patient with mild parkinsonian rigidity and little tremor. Passive stretch of the extensors produces a complex, irregular build up of activity with units appearing and then falling out again (Fig. 11a). This is more clearly seen when the flexors are stretched (Fig. 11b) and there is definite grouping of action potentials at about 7 per second (which may represent the tremor rate in this patient) at the beginning of stretch. As stretch progresses there are little silent periods at irregular intervals, which almost certainly are lengthening reactions which thus allow the muscle to take up the length imposed upon it. This is, then, the plasticity of parkinsonian rigidity. Furthermore, the electromyogram may not necessarily be silent when the antagonistic muscle is stretched thus relaxing the agonist (lower record Fig. 11a), and it is then apparent that there is firing of a few motor units almost synchronously at a rate of 7 per second and each burst often corresponds with a little reduction in activity in the antagonist which must add to the plastic properties of this type of rigidity. In both the extensors (Fig. 11c) and in the flexors predominantly (Fig. 11d), the tremor rhythm is apparent at the onset of voluntary contraction but tends to smooth out as contraction reaches a maximum.

\section{Effects of Procaine on Parkinsonian Rigidity}

Twenty-five cases have been studied and the cases selected have all shown a predominantly rigid picture rather than tremor, though, of course, the latter was often present as well. The present results have been very uniform and confirm those reported by Walshe (1924).

Case 7.-E.T., a woman aged 63, had Parkinson's disease for 18 months beginning in the right hand with

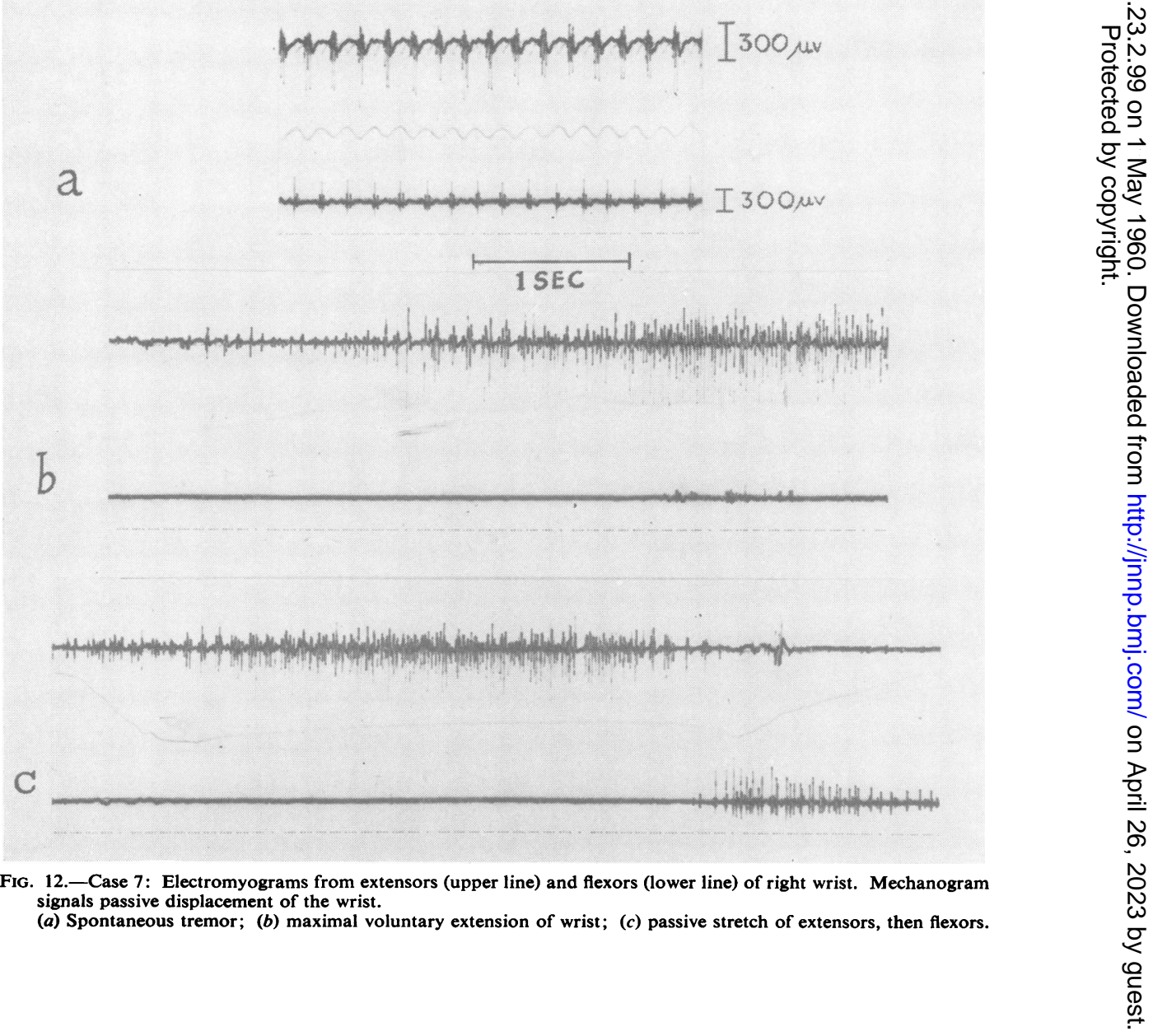




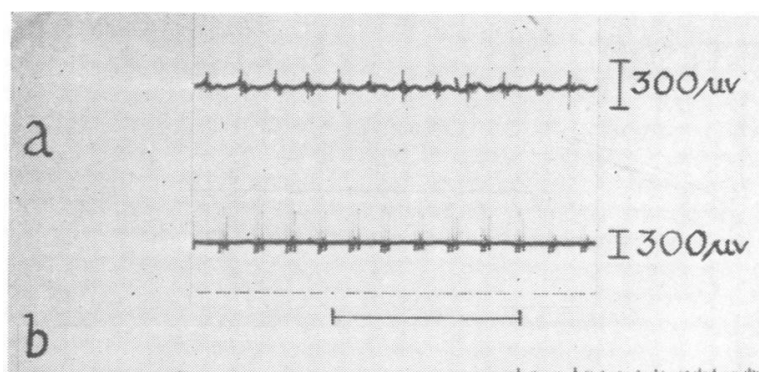

FIG. 13.-Same case as Fig. 12, three minutes after procaine injection into extensors.

(a) Spontaneous tremor, fewer units take part in the extensors; (b) stretch response of extensors reduced.

tremor; this with slowness of movement are now the predominating symptoms. In August, 1957, simultaneous recordings were taken from co-axial needles in the extensor and flexor muscles of the right wrist, and the mechanogram was recorded from the extensor surface of the wrist. The spontaneous tremor at rest was recorded (Fig. 12a) and shown to be alternating between the flexors and the extensors. The onset of voluntary contraction of the extensors of the wrist (Fig. 12b) was slow, tremulous but powerful. Stretching the extensors, however, evoked an almost equally large irregular and intermittent outburst (Fig. 12c) which has already been described as typical of parkinsonian rigidity. The stretch reflex of the flexor muscles in this patient was relatively brief.

After these initial recordings had been taken, $5 \mathrm{ml}$. of $1 \%$ procaine was infiltrated fan-wise into the extensor muscle near its motor point. Three minutes later (Fig. 13) the spontaneous tremor of the extensor muscle was reduced in amplitude, though the rate remained the same as before (Fig. 13a). Only one or two action potentials were seen in each tremor beat of the extensor while previously at least four and often six or seven could easily be identified. The spontaneous tremor and stretch reflex of the flexor muscle remained unaltered. The stretch reflex of the extensor muscle, however, was much reduced (Fig. 13b). Five minutes after the procaine injection (Fig. 14) the spontaneous tremor in the extensor muscle was still present, but much reduced in size and in number of units firing (Fig. 14a). Maximal voluntary activity of the extensor (Fig. 14b) was of large amplitude and slightly irregular and certainly no smaller than before the procaine injection. On the other hand, the stretch reflex of the extensor muscle had disappeared (Fig. 14c), while that of the flexor remained unaltered. Thirty-five minutes later (Fig. 15) the tremor amplitude and number of units firing was much the same (Fig. 15a) and voluntary contraction was at first tremulous before the maximum was recorded (Fig. 15b). Its amplitude was comparable to that in Fig. 14. The stretch reflex in

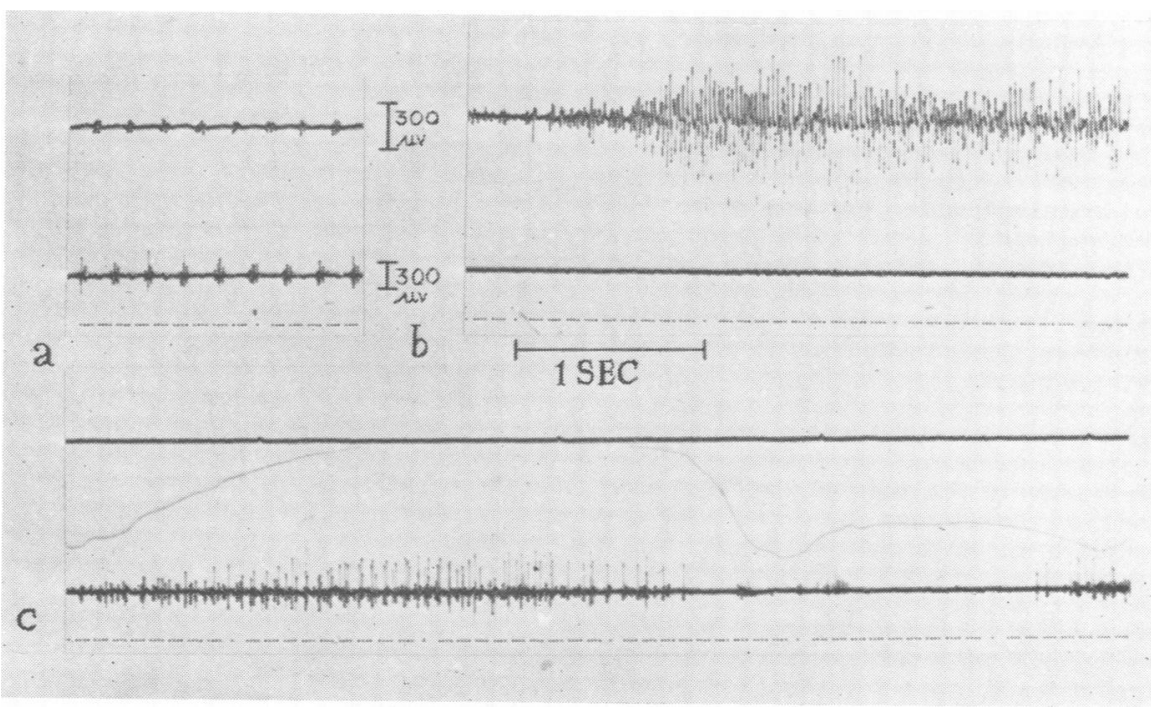

FIG. 14.-Same case as Fig. 12, five minutes after procaine injection into extensors.

(a) Spontaneous tremor, few units present in extensors; (b) voluntary extension of wrist shows large amplitude outburst of motor unit potentials; (c) no stretch reflex in the extensors. but a good one remains in the flexors. 


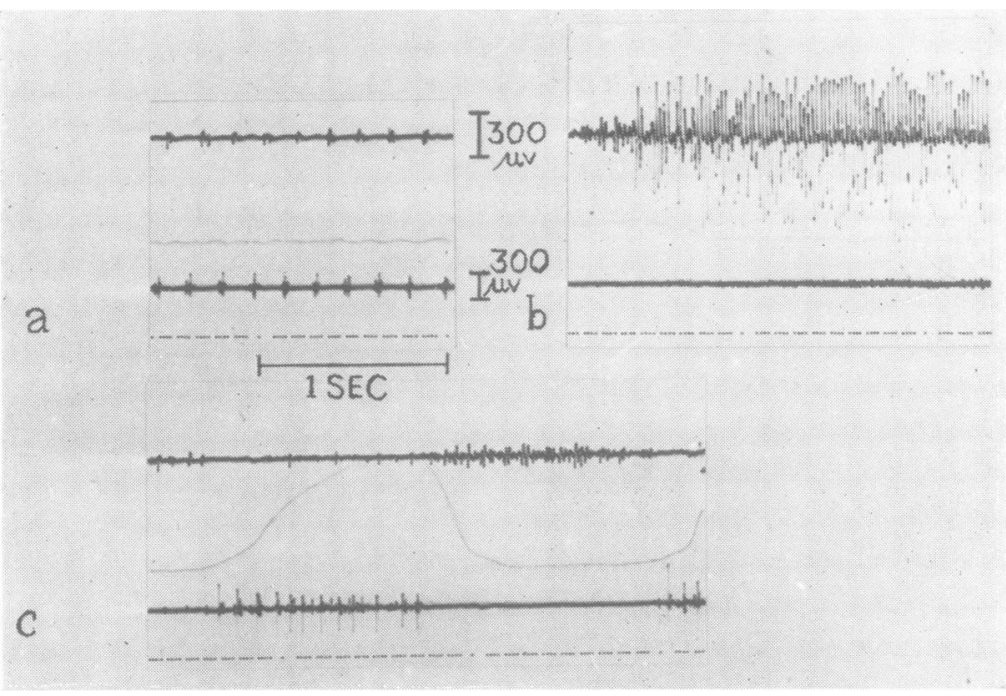

Fig. 15.-Same case as Fig. 12, 35 minutes after procaine injection.

(a) Spontaneous tremor; (b) maximal extension of wrist; $(c)$ a small stretch reflex is now returning to the extensors.

the extensors was quite small, three or four units only recruiting and falling out in the manner so characteristic of plastic rigidity (Fig. 15c).

The rigidity of the extensors of the wrist in this patient did not fully return to the pre-injection level during the total period of observation (three hours), though it was sought for both clinically and electromyographically.

In parkinsonian rigidity procaine has a clear differential action on the rigidity, which it abolishes, and on motor power, which is preserved. The tremor continues in the injected muscle at the previous rate, but fewer motor units seem to partake.

\section{IV.-Effects of Procaine in Dystonia and Tetanus}

By dystonia we mean a state of abnormal posture of a limb or limbs (either in flexion or extension) with increasing resistance to passive movement which may be intense. The dystonic muscles do not show the lengthening reaction and the limb always returns to its previous posture when the imposed displacement is relaxed. It is in this respect, the very opposite of the plastic rigidity of parkinsonism, which allows the limb to assume any posture imposed upon it.

Four patients with dystonic arms have been studied; two had Wilson's disease and two had had a cerebral haemorrhage several weeks previously. They all had flexed arms which resisted attempts of passive extension and could not be extended voluntarily. Two of these patients were considered to have "contracture" of the biceps. Voluntary activity of the biceps was present but hard to assess and the biceps jerk was apparently absent. Ten millimetres of $1 \%$ procaine were injected fan-wise near the motor point of the biceps muscle and within 10 minutes the arm could be extended to $150^{\circ}$ and a biceps jerk was elicited. Voluntary power of flexion was very strong. Over the next half hour this state remained and then the dystonia gradually returned so that at the end of two hours it was almost fully back.

These cases were of interest as they showed that "contracture" of dystonic muscles is not the whole picture and that independently of any pathological shortening of tendon or muscle, reflex factors through the mediation of the gamma fibres of the muscle spindle are responsible for the abnormal posture.

One case of tetanus has been studied.

This was a boy of 6 (B.L.) who had contracted severe tetanus 12 weeks before the experiment to be described below. He had required curarization and positive pressure respiration for six weeks. After these measures had been stopped many of his muscles, particularly antigravity muscles, were stiff. Thus he still had trismus, and the arms were held in a flexed almost dystonic posture, as were the thighs and legs. The arms were almost fully flexed in the resting posture, but he was able voluntarily to extend them to about $75^{\circ}$. He was thought to have moderately severe contracture of all the affected muscles though the tendon jerks were all present and very brisk.

On February 28, 1957, $5 \mathrm{ml}$. of $1 \%$ procaine was infiltrated into the left biceps muscle near the motor point. Within seven minutes the arm could be extended voluntarily to $135,^{\circ}$ power of the biceps was strong, and 
the tendon jerk brisk. Within 45 minutes, however, the original posture had been resumed and the arm could only be extended $90^{\circ}$.

This case again illustrated the overemphasis of the clinicians on contracture instead of an exaggerated stretch reflex. It also shows that the increased stretch reflexes of some stages of tetanus can be differentially reduced by procaine without affecting voluntary power adversely.

\section{Discussion}

The interpretation of the experiments described above depends on what is already known about the action of dilute procaine solutions on the innervation of muscles, whether it is injected around the nerve itself or near the motor point. Branching of large motor nerve fibres frequently begins near the latter region and each individual branch has a diameter less than its parent and would therefore be expected to be more susceptible to the action of a local anaesthetic. Nevertheless motor power may persist unaltered when quite large amounts of dilute procaine are injected near the motor point.

The muscular nerve contains large afferent fibres (13-20 $\mu$ ) derived from the annulo-spiral endings of muscle spindles and the Golgi tendon organs (Group Ia and Ib afferents), smaller afferent fibres $(4-12 \mu)$ originating in the flower spray endings of the muscle spindle (Group II afferents), and small $(1-4 \mu)$ afferent fibres (Group III afferents) from the intramuscular septa and blood vessels (Lloyd and Chang, 1948; Adams, Denny-Brown, and Pearson, 1953). Two-thirds of the afferent fibres in the muscular nerve are large motor fibres (alpha efferents, $8-14 \mu$ ) and destined to supply all muscle fibres except those of the muscle spindle (Eccles and Sherrington, 1930) and the remaining third are small $(2-7 \mu)$ motor nerve fibres (gamma efferents) which specifically innervate the intrafusal muscle of the muscle spindle.

It has been known for a number of years that the cocaine group of local anaesthetics tends to block small nerve fibres in preference to large ones (Gasser and Erlanger, 1929), and Matthews and Rushworth (1957b) showed that in the special case of the muscular nerve, the gamma motor fibres were preferentially blocked by dilute procaine. Stronger solutions of procaine did block the larger fibres, however, the large motor fibres being slightly more susceptible than the large afferents.

At a time when the gamma fibres were blocked by dilute procaine, large motor nerve fibres could transmit a motor tetanus of 100 per second and also high afferent discharges from the muscle spindle could be evoked (Matthews and Rushworth, 1958).
It was not until both the large afferents and the large motor fibres were actually dropping out that the problem of the refractory period began to show itself.

Another series of experiments by Matthews and Rushworth (1957a) showed that the stretch reflex and tendon jerk of the soleus muscle of decerebrate cats were very rapidly abolished by $0 \cdot 2 \%$ procaine when this was applied to the nerve, though the motor tetanus at 100 per second was unaffected. They interpreted these results in terms of a preferential block of the gamma motor fibres at a time when neither the large (alpha) motor fibres nor the large proprioceptive fibres (Group I) were affected.

In the present experiments on patients with spasticity, rigidity, or dystonia, selective block of gamma motor fibres to muscle spindles by procaine leaving large motor fibres and large sensory fibres intact is an adequate explanation of the differential abolition of the exaggerated stretch reflex without affecting motor power. Sarnoff and Arrowood (1947) reported a similar phenomenon when they described the abolition of knee and ankle jerks by $0.2 \%$ intrathecal procaine while voluntary power and position sense remained intact. At that time an adequate explanation was not available.

Recently, intrathecal phenol has been used to alleviate spasticity (Nathan, 1959; Kelly and Gautier-Smith, 1959), following the lead given by Maher (1955 and 1957) and Brown (1958) that this substance can be used to destroy small nerve fibres in either dorsal or ventral roots. In this respect it behaves like procaine except that the block is permanent. Alcohol too has similar properties on nerve fibres, but though it has had its advocates (Cooper and Hoen, 1949) it is not really suitable for intrathecal therapy due to its irregular and poor penetration and to the adhesive arachnoiditis that occasionally follows its use. It would appear that the beneficial effects of alcohol and phenol on spasticity depend on the preferential permanent blocking of gamma motor fibres in the ventral roots.

Some of the unexplained long-lasting effects of procaine blocks in spastic patients may be attributed to the $0.2 \%$ chlorocresol which is often mixed with procaine to preserve it. One would expect chlorocresol to have similar properties to phenol.

In the present experiments on spastic patients procaine has usually abolished the clonus, resistance to passive displacement, and the ankle jerk in this order, at a time when the motor response was not reduced. The abolition of the ankle jerk by procaine is, as Matthews and Rushworth pointed out (1957a), the converse of Jendrassik's manoeuvre ("reinforcement") which is known to excite the gamma motoneurones (Paillard, 1955). 
Often voluntary power was even increased as much as $20 \%$ when the stretch reflexes had been abolished with procaine, and occasionally during the progressive block a stage might be reached when the ankle jerk was actually increased though the resistance to passive stretch and clonus was absent (Case 5).

The convergence of a number of reflexes on to a common motoneurone pool may result in a number of reflex phenomena, among them that of "occlusion" (Creed, Denny-Brown, Eccles, Liddell, and Sherrington, 1932). This principle explains how the resultant of two reflexes acting together may be less than the sum of each acting individually. Occlusion of the tendon jerk by the stretch reflex was beautifully shown by Denny-Brown (1928) in the quadriceps of a decerebrate cat. The initial tension of the myograph was high (about $4 \mathrm{lb}$.) (this was largely stretch reflex) and the knee jerk could hardly be seen superimposed on this high tension. The stretch reflex of the quadriceps was then inhibited by pulling on the tendon of the iliopsoas, and now the knee jerk was seen as a large amplitude response but not exceeding the tension of the original stretch reflex. As the inhibitory stimulus was withdrawn, the large toxic stretch reflex of the quadriceps gradually returned and with this the knee jerk progressively declined again.

In the present experiments "voluntary" activity and the tendon jerk were competing for motoneurones against a background of a hyperactive tonic stretch reflex which dominated the same motoneurones. Desensitization of the stretch response of the muscle spindle by blocking the gamma motor fibres with procaine kept the stretch reflex in abeyance but now allowed the synchronized afferent volley from the tendon jerk to have a wider access to motoneurones and also voluntary activity likewise. Thus severe spasticity may occlude some voluntary movement (and the tendon jerk), and these may be increased when the exaggerated tonic stretch reflex is reduced.

The classical decerebrate rigidity of animals, spasticity in man, and parkinsonian rigidity are all due to increased tonic stretch reflexes and are reduced or abolished if the appropriate dorsal roots are cut (Sherrington, 1898; Förster, 1911, 1913a and b; Hey Groves, 1911; Pollock and Davis, 1930). The stretch reflexes in these conditions have already received a certain amount of study (Liddell and Sherrington, 1924; Hoefer and Putnam, 1940; Rondot, Dalloz, and Tardieu, 1958). But the fundamental disorder of physiology which determines the difference between the parkinsonian plastic type of rigidity, the statuesqueness of the dystonias, and clasp-knife spasticity is not entirely clear. The distribution of stretch reflexes in either agonist or antagonist or both, however, must be highly significant and cause much reflex interplay at the spinal level. The electromyogram in parkinsonian rigidity shows that the lengthening reaction occurs with each increment of movement and this accounts for the plasticity of the rigidity. We think of the lengthening reaction as being an inhibitory mechanism due to the discharge of Golgi tendon organs, but this may not be the whole story in this type of rigidity, for we know that certain reflexes between agonist and antagonist are exaggerated in this condition. The Westphal phenomenon in parkinsonism is an example of this (Denny-Brown and Rushworth, to be published), for when the foot is suddenly dorsiflexed the shortened muscles contract. This so-called "paradoxical stretch reflex" is due to proprioceptive discharge from the antagonists, and disappears when these are injected with procaine.

The abolition of hyperactive stretch reflexes by injecting procaine in the gamma motor fibres suggests that in spasticity, rigidity, and dystonia the gamma motoneurones are overactive, thus increasing the sensitivity of the annulo-spiral ending of the muscle spindle to stretch. This in turn produces tetany in the motoneurones and a state of posttetanic potentiation can thus be established (Granit, 1955, 1956). Gamma motoneurones can be excited and inhibited both at the cord level (Hunt, 1951; Kobayashi, Oshima, and Tasaki, 1952; Granit, Job, and Kaada, 1952; Eldred and Hagbarth, 1954) and from various supraspinal structures including the reticular formation and motor cortex (Granit and Kaada, 1952; Eldred et al., 1953). Plurality of origin of excitatory and inhibitory balance of the normal gamma motoneurones might account for the frequency of hyperactive stretch reflexes as a sign of disease of the central nervous system.

One of the present cases (Case 6) showed no differential action of procaine between the stretch reflex and motor power and in this respect was analogous to the experiments of Matthews (1958) on the effects of procaine on the rigidity of the Pollock and Davis type of anaemic decerebrate cat. In this case the spasticity is maintained by alpha motoneurones alone and is not abolished by dorsal root section. This type of spasticity was only seen in one instance in the present study and is probably unusual, but the present cases were all selected to have at least measurable voluntary activity, and the stretch reflexes of the completely isolated spinal cord have not been examined.

While the exaggerated stretch reflex is certainly an important basic disorder of function in spasticity, rigidity, and dystonia, it is not the only one as 
Denny-Brown has pointed out (1950). Not only are stretch reflexes of certain muscles hyperactive, but they are also more susceptible to other proprioceptive stimuli whether from other muscles or the labyrinth. Other modalities of stimuli also seem to be channelled into facilitating the stretch reflex and only pain may inhibit it. This may account for much of the disorder of voluntary movement in spastic paresis, parkinsonism, and dystonia.

\section{Summary}

The evolution of experiments and ideas leading to the stretch reflex are traced and the superfluity of the term "tonus" is re-emphasized.

A method of investigating patients with spasticity, rigidity, and dystonia is described and is based on experiments with 50 patients.

Dilute procaine injected near the muscular nerve results in abolition of the hyperactive stretch reflexes, while voluntary activity is preserved and often slightly increased.

Reasons are given for believing that this is due to a selective action of procaine on the gamma motor fibres of the muscle spindle.

The stretch reflexes of spasticity and parkinsonian rigidity are compared and the dependence of these states on gamma motoneurones is discussed.

Occlusion of voluntary movement and tendon jerks by high tonic stretch reflex is described.

One case only showed no differential action on stretch reflex and voluntary power, and spasticity in this single case was no doubt maintained by alpha motoneurones alone, independently of the gamma fibres.

It has been suggested that a possible explanation of the long-lasting effects of procaine in relieving spasticity and rigidity may be due to the $0.2 \%$ chlorocresol which is often mixed with procaine solutions to preserve them. This may act like phenol in blocking gamma motor fibres more permanently.

It is a great pleasure to thank Dr. Ritchie Russell, who has most kindly placed many patients at my disposal, and I am most grateful to him for providing the excellent facilities for this work and giving his unstinted support, advice, and encouragement.

I wish also to record my gratitude to Professor D. Denny-Brown for the generosity of his own time and practical help in investigating some of these patients and also for much stimulating discussion. Professor E. G. T. Liddell has been a constant help from the very beginning, and I am most grateful to him for support and encouragement as well as the inspiration of his own brilliant work on stretch reflexes and experimental rigidities. Dr. C. G. Phillips has given freely of his advice and encouragement. Dr. E. L. Poole and Dr. P. B. C. Matthews did the first experiment in collaboration with myself, and I am grateful for their help.

Some of this work was reported at the National Spastics Society Study Group on Child Neurology, Oxford, in September, 1958 (Rushworth, 1959), and I am most grateful to the N.S.S. for a grant for apparatus. A grant from the Wellcome Trust made the work at Boston City Hospital possible. The Cairns' Fund provided support for much of the apparatus and running costs of the Oxford work.

\section{REFERENCES}

Adams, R. D., Denny-Brown, D., and Pearson, C. M. (1953). Diseases of Muscle. Hoeber, New York.

Adriani, J. (1954). Nerve Blocks. A Manual of Regional Anaesthesia for Practitioners of Medicine. Thomas, Springfield, Illinois.

Bennett, A. H. (1888). Brain, 10, 289.

Bremer, F., and Titeca, J. (1930). C.R. Soc. Biol. (Paris), 105, 873.

Brondgeest, P. J. (1860). De tono musculorum voluntati subidorum. Holl. Beitr. anat. physiol. Wiss. Quoted by Fulton, J. F. (1926).

Brown A. S. (1958), Lancet, $2,975$.

Cobb, S., and Wolff, H. G. (1932). Arch. Neurol. Psychiat. (Chicago), 28,661 .

Cooper, I. S., and Hoen, T. I. (1949). J. Neurosurg., 6, 187.

Creed, R. S., Denny-Brown, D., Eccles, J. C., Liddell, E. G. T., and Sherrington, C. S. (1932). Reflex Activity of the Spinal Cord. Clarendon Press, Oxford.

Denny-Brown, D. (1928). On the Essential Mechanism of Mammalian Posture. D.Phil. Thesis, Oxford. (1929) Proc roy Soc B $104,252$.

(1950). J. nerv. ment. Dis., 112, 1 .

- and Rushworth, G. To be published.

Eccles, J. C., and Sherrington, C. S. (1930). Proc. roy. Soc. B., 106, 326 .

Eldred, E., Granit, R., and Merton, P. A. (1953). J. Physiol. (Lond.), $122,498$.

-, and Hagbarth. K.-E. (1954). J. Neurophysiol., 17, 59.

Floyd, W. F., and Silver, P. H. S. (1951), Lancet, i, 133

Förster, O. (1911). lbid., 2, 76 .

(1913a). Relations between Spasticity and Paralysis in Spastic Paralysis. In Proceedings of $17 \mathrm{th}$ International Congress of Medicine, London, 1913. Section XI. Neuropathology, Pt 2, pp. 55-64.

- (1913b). Brit. med. J., 2, 798.

Fulton, J. F. (1926). Muscular Contraction and the Reflex Control of Movement. Williams and Wilkins, Baltimore.

Gasser, H. S., and Erlanger, J. (1929). Amer. J. Physiol., 88, 581.

Granit, R. (1955). Receptors and Sensory Perception. A Discussion of Aims, Means and Results of Electrophysiological Research into the Process of Reception. Yale University Press, New Haven.

(1956). J. Physiol. (Lond.), 131, 32.

Job, C., and Kaada, B. R. (1952). Acta. physiol. scand., 27, 161.

Grove, and Kaada, B. R. (1952). Ibid., 27, 130.

Groves, E. W. Hey (1911). Lancet, 2, 79.

Hoefer, P. F. A. (1941). Arch. Neurol. Psychiat. (Chicago), 46, 947.

-, and Putnam, T. J. (1940). Ibid, 43, 1 .

Hunt, C. C. (1951). J. Physiol. (Lond.), 115, 456.

Kelly, R. E. and Gautier-Smith, P. C. (1959). Lancet, 2, 1102

Kobayashi, Y.. Oshima, K., and Tasaki, I. (1952). J. Physiol. (Lond.), 117,152 .

Liddell, E. G. T., and Olmsted, J. M. D. (1929). J. Physiol. (Lond.), 67,33 .

- and Sherrington, C. S. (1924). Proc. roy. Soc. B., 96, 212.

Liljestrand, G., and Magnus, R. (1919). Pflüg. Arch. ges. Physiol., 176, 168.

Lloyd, D. P. C., and Chang, H.-T. (1948). J. Neurophysiol., 11, 199.

Maher, R. M. (1955). Lancet, 1, 18

Man-(1957). Ibid., 1, 16.

Matthews, P. B. C. (1958). J. Physiol. (Lond.), 140, 408.

, and Rushworth, G. (1956). Ibid., 131, 30P.

- - (1957a). Ibid., 135, 245.

- - (1957b). Ibid., 135, 263. Mommsen, J. (1885). Virchows Arch. path. Anat., 101, 22. Quoted

Nathan, P. W. (1959). Lancet, 2, 1099. 
Paillard, J. (1955). Réffexes et régulations d'origine proprioceptive chex l'homme. Etude Neurophysiologique et psychologique., p. 289. Arnette, Paris.

Pollock, L. J., and Davis, L. E. (1923). Arch. Neurol. Psychiat. (Chicago), 10, 391,

- - (1930). Ibid., 23, 303.

Ra (1931). Amer. J. Physiol., 98, 47.

Et. clin. biol., 3, 585 .
Rushworth G. (1959). Cerebral Palsy Bulletin No 7,p. 3.

Sarnoff, S. J., and Arrowood, J. G. (1947). J. Neurophysiol., 10, 205. Seyffarth, H., (1942). Nord. Med., 14, 1569. Quoted by Joseph and Nightingale (1952).

Sherrington, C. S. (1898). J. Physiol. (Lond.), 22, 319.

- (1915). Brain, 38, 191 .

(1931). Quoted by Cobb and Wolff (1932).

Walshe, F. M. R. (1924). Brain, 47, 159 .

Weddell, G., Feinstein, B., and Pattle, R. E. (1944). Ibid., 67. 178.

\section{THE FEBRUARY (1960) ISSUE}

The February (1960) issue contains the following papers:-

A Clinical and Electrical Study of Ulnar Nerve Lesions in the Hand. Peter Ebeling, R. W. Gilliatt, and P. K. Thomas.

Effects of Posterior Root Section on the Activity of Some Muscles in Man. P. W. Nathan and T. A. Sears. Observations on 500 Cases of Migraine and Allied Vascular Headache. George Selby and James W. Lance.

Neurological, Electroencephalographic, and Heredo-familial Aspects of Pseudohypoparathyroidism and Pseudo-pseudohypoparathyroidism. L. G. Dickson, Y. Morita, E. J. Cowsert, J. Graves, and J. S. Meyer.

Hartnup Disease in Psychiatric Practice: Clinical and Biochemical Features of Three Cases. L. A. Hersov and R. Rodnight.

Congenital, Static Familial Ophthalmoplegia. F. Lees.

A Clinical Trial of Dehydroepiandrosterone (Diandrone). A. D. Forrest, J. Drewery, K. Fotherby, and S. G. Laverty.

A Rating Scale for Depression. Max Hamilton.

Clinical and Electromyographic Studies of "Spinal Reflexes" in Premature and Full-term Infants. I. Fényes, Ch. Gergely, and Sz. Tóth.

Fatal Encephalopathy in Glandular Fever. J. D. Bergin.

The Incidence and Characteristics of Lewy Bodies in Idiopathic Paralysis Agitans (Parkinson's Disease). J. Bethlem and W. A. den Hartog Jager.

Proceedings of the Society of British Neurological Surgeons: 60th Meeting.

Book Reviews.

A number of copies are still available and may be obtained from the Publishing Manager, British Medical Association, Tavistock Square, W.C.1, price 17s. $6 d$. 